\title{
Convite à dança
}

José Helder Pinheiro Alves

Universidade de Campina Grande - PB

Eu danço tu danças nós dançamos

Sempre dentro de um círculo implacável de luz

Sem saber quem nos olha atenta ou distraidamente no escuro.

Mário Quintana

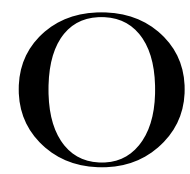

motivo da dança é pouco freqüentado em nossa tradição lírica. Um inventário parcial aponta um ou outro poema no conjunto da poesia romântica, poemas e versos esparsos entre os modernistas, exceção feita a Cecília Meireles, que visitou o motivo em diversos poemas e nos deixou uma extraordinária crônica, "Os dançarinos", ${ }^{1}$ em que fala sobre a natureza da dança. Mário de Andrade com o seu "Dança" (Remate de males) nos legou um poema mais longo.

João Cabral de Melo Neto nos trouxe o ritmo e o mistério da bailarina espanhola em dois poemas: "Estudo para uma bailadora Andalusa" e "Uma bailadora Sevilhana".

É na poesia dedicada ao público infantil que o motivo é mais recorrente, sobretudo com a exploração da imagem da bailarina. Cecília nos legou um poema precioso, "A bailarina," hoje retomado por inúmeros poetas que não alcançaram o nível de ludismo da poetisa de Ou isto ou aquilo. O certo é que no país do samba, do frevo, do forró, dentre outros ritmos e danças, o motivo da dança ainda não foi descoberto em todas as suas virtualidades pelos poetas.

\section{Na rua dos cataventos}

Os poemas ligados ao motivo da dança na poesia de Mario Quintana revelam, quase sempre, uma dimensão convocatória. Dançar

${ }^{1}$ MEIRELES, 1998, p. 157-158. 
é encontrar um ritmo que permita viver as experiências humanas de modo significativo. A dança, portanto, parece assumir um caráter transcendente, algo mais que um mero divertimento ou passatempo. Antes, seria um modo mais adequado de viver o tempo em sua instantaneidade. O motivo da dança parece constituir na poesia de Quintana uma metáfora de um certo modo de viver a vida, de encantar o tempo, surpreendê-lo, vivenciar instantes infinitos.

Cinco dos trinta e cinco sonetos de A rua dos Cataventos fazem referência à dança, ora ligada a objetos, ora a pessoas.

"O soneto I" figura um momento de metamorfose lírica, isto é, um instante em que o poeta nos apresenta uma experiência de contemplação no ambiente de trabalho, e que, de um momento para outro, ocorre uma mágica inserção do eu lírico no objeto contemplado:

Escrevo diante da janela aberta.

Minha janela é cor das venezianas:

Verde!... E que leves, lindas filigranas

Desenha o sol na página deserta!

O segundo quarteto dá continuidade à descrição, agora de um modo interrogativo. Mas é o primeiro terceto que nos traz a imagem da dança:

Jogos de luz dançando na folhagem!

Do que ia escrever até me esqueço...

Pra que pensar? Também sou da paisagem...

Como se vê, a natureza dança e vai contaminando o eu lírico que esquece o que "ia escrever" para, a seguir, integrar-se à cena descrita: "Também sou da paisagem..." O esquecimento indica a atitude de entrega, de suspensão instantânea do cotidiano. ${ }^{2}$

\footnotetext{
${ }^{2}$ A suspensão indicia um estilo de dança de caráter dionisíaco. Nietzsche em diferentes momentos de sua obra nos oferece exemplos desse tipo de dança. Destaco um fragmento de seu Zaratustra: "Aprendi a caminhar; desde então, gosto de correr. Aprendi a voar; desde então, não preciso de que me empurrem para sair do lugar. Agora estou leve; agora vôo; agora, vejo-me debaixo de mim mesmo; agora, um deus dança dentro de mim" (Canto "Do ler e escrever", p. 58). Trata-se, como se vê, de uma metamorfose, de um momento de êxtase possibilitado pela dança. Formalmente, veja-se a gradação que se opera: caminha, corre, voa e que sugere o movimento de afastamento do chão e pode indiciar estado de transe.
} 
O "soneto XIV" nos coloca a seguinte situação: o eu lírico ao ouvir uma voz (um canto), acorda assustado, com "frêmito" nas mãos ( $1^{a}$ estrofe); retorna "Depois" à calma, e imagina o brilho das lâmpadas quebradas, que dançam ao luar. Trata-se de um devaneio em que está projetada uma metáfora de grande interiorização: as "lâmpadas quebradas" sugerem, entre outras possibilidades, os sonhos que perderam o brilho, ou ideais não alcançados.

E quando a lua, enorme, nas estradas

Surge... dançam as minhas lâmpadas quebradas

Ao vento mau que as apagou...

O eu lírico dirá, no final, que a voz que o acordou é a "voz do morto que cantou". Antes, o poeta já se referiu à "noite alucinada", o que reforça a idéia de que o soneto é um devaneio lírico, no meio da noite, sobre as perdas acumuladas na vida. A dança das "lâmpadas quebradas/ Ao vento mau que as apagou", conferem um tom ameno à perda.

A convivência pacífica com a morte é o tema do soneto XIX. A dança se dá entre o eu lírico e a morte:

E dançamos de roda ao luar amigo

$\mathrm{Na}$ pequenina rua em que vivi.

O ambiente ("pequena rua", "luar amigo") em que ocorre a dança é simples, acolhedor e remete à passividade do eu lírico no contato com a morte.

O "soneto XXVII" descreve uma possibilidade de transfiguração do real. O poema inicia-se com um "Quando" que remete a vários acontecimentos ocorridos. Depois que se deram esses fatos, a natureza será modificada:

Encheremos o céu de vôos encantados!...

$\mathrm{E}$ as rosas da Cidade inda serão mais rosas,

Serão todos felizes, sem saber por quê...

Até os cegos, os entrevadinhos...

Não há como não lembrar uma grande celebração dionisíaca, um grande ditirambo. ${ }^{3} \mathrm{E}$ na estrofe final, para coroar todos os feitos extraordinários, temos a retomada da imagem da dança:

\footnotetext{
${ }^{3}$ Lembro mais uma vez as reflexões de Nietzsche no "Canto do túmulo" de seu Assim falou Zaratustra: "somente dançando, sei falar em imagens das coisas mais elevadas." (p. 125) Observe-se a prioridade que o gesto dançante assume em detrimento do conceito, do discurso racional.
} 
Vestidos, contra o azul, de tons vibrantes e violentos,

Nós improvisaremos danças espantosas

Sobre os telhados altos, entre o fumo e os cataventos!"

O clima surreal permanece na indicação do palco da dança. A imagem do catavento retornará de modo central, logo mais, em "Canção da primavera". Diferentemente dos dois poemas anteriores, a dança aqui é um gesto realizado pelo estranho coral "de grandes olhos claros e rasgados". Não devemos esquecer que o poema se constrói como um projeto, já que imagina e anuncia o futuro, como atestam os verbos "seremos", "encheremos", "serão", "improvisaremos".

O único poema que apresenta a dança como motivo central é "soneto XXIV." Trata-se de uma experiência específica de dança, a ciranda, que assume aqui uma feição simbólica. ${ }^{4}$

\section{Soneto XXIV}

Para Lino de Mello e Silva

01 A ciranda rodava no meio do mundo, No meio do mundo a ciranda rodava. E quando a ciranda parava um segundo, Um grilo, sozinho no mundo, cantava...

05 Dali a três quadras o mundo acabava. Dali a três quadras, num valo profundo... Bem junto com a rua o mundo acabava... Rodava a ciranda no meio do mundo...

E Nosso Senhor era ali que morava, 10 Por trás das estrelas, cuidando o seu mundo...

E quando a ciranda por fim terminava

E o silêncio, em tudo era mais profundo, Nosso Senhor esperava... esperava...

Cofiando as suas barbas de Pedro Segundo.

\footnotetext{
${ }^{4}$ O Dicionário de folclore brasileiro, de Câmara Cascudo, define ciranda como "dança infantil, de roda, vulgaríssima no Brasil e vinda de Portugal, onde é bailado de adultos."
} 
O poema se impõe, inicialmente, pela musicalidade. As repetições de palavras (mundo, ciranda), as rimas em undo e ava que também ressoam no interior de alguns versos, conferem-lhe um ritmo embalante, com gosto de acalanto. Acompanhando os passos desta dança, observese que há momentos distintos e complementares. O primeiro quarteto articula bem o ritmo da dança e nos dá notícia de uma momentânea parada e imediata entrada em cena de um grilo. O palco da ciranda é "o meio do mundo", portanto, não há precisão de lugar. A notícia de que o mundo "acabava" bem próximo vem-nos no segundo quarteto, que conserva as mesmas rimas, numa espécie de eco da dança iniciada anteriormente. Aqui os espaços são apontados: "valo profundo", "bem junto com a rua" e "no meio do mundo". O primeiro terceto é iniciado por uma aditiva que nos sugere uma junção do que vinha sendo apresentado com algo de novo. Há um ser que ordena e cuida "o seu mundo". O fim da ciranda contamina "tudo" de silêncio (último terceto).

Instala-se uma tensão entre "o meio do mundo" e "Dali a três quadras...". Por outro lado, o verso 07 reúne o distante e o próximo: "Bem junto com a rua o mundo acabava." Parece-nos que o poeta articula no poema uma perspectiva um tanto mítica, isto é, o eu lírico vê um mundo ordenado, com um centro, um Deus que, "Por trás das estrelas", vive "cuidando o seu mundo...". A repetição de "ciranda" contribui para a sensação de "circularidade".

A imagem do grilo, que canta solitário na noite, escondido no seu canto, é, na poesia de Quintana, remetida ao poeta. O verso 04 ("Um grilo, sozinho no mundo, cantava...") articula essa dimensão do poeta-grilo. Quando tudo é silêncio, quando a "ciranda" da vida é suspensa, o poeta canta no meio da noite. ${ }^{5}$

Na Rua dos cataventos, como se vê, o motivo da dança não assume um caráter central nos poemas. Aparece de modo remissivo, embora alguns poemas já anunciem um modo de figuração mais complexo.

\footnotetext{
${ }^{5}$ Solange Yokozawa, ao analisar este soneto afirma: "O movimento circular evocado por ambas as leituras, tanto pela brincadeira de roda quanto pela ciranda da vida, encontra correspondência na exploração dos elementos musicais. Desse modo, em nível fônico, o texto também desenvolve um movimento circular, que o poeta foi buscar na conhecida cantiga infantil: Ó ciranda, ó cirandinha, (...). Novamente, é o ritmo de uma brincadeira de roda, do nosso folclore, da rua, que palpita em um quintanar." (YOKOZAWA, s. d., p. 179/80)
} 


\section{E dançamos em roda}

Dos 35 poemas que compõem Canções, segundo livro do poeta, quatro têm na dança o motivo central. Em "Canção da Chuva e do Vento", somos colocados diante de uma espécie de roteiro para a dança. Os passos a serem dados ("Põe um pé. Põe outro pé."), o andamento a ser seguido ("Mais depressa. Mais depressa", "Mansinho, agora, mansinho") e os movimentos ("Upa. Salta. Pula. Agacha") são claramente apontados.

$\mathrm{Na}$ "Canção do Primeiro do Ano", o poeta representa a festa que se arma no ano novo através da imagem da dança. Dois momentos figuram a aproximação de seres e objetos através da dança. Na quinta estrofe temos:

E os sinos dançam no ar.

De casa a casa, os beirais,

- Para lá e para cá -

Trocam recados de asas,

Riscando sustos no ar.

O animismo dos objetos em tempo de festa, novamente aponta o caráter renovador que a dança imprime ao meio. No final da última estrofe temos uma cena em que a cidade é como que contaminada pela dança dos sinos:

E levada pelos sinos,

Toda ventando de sinos,

Dança a cidade no ar!

A dança aqui é instrumento de aproximação entre as pessoas, como costuma acontecer nas grandes festas que comemoram passagens. $\mathrm{O}$ primeiro dia do ano, ciclo novo que se inicia, é recebido no poema com uma verdadeira dança de sons, numa bela sinestesia. ${ }^{6}$

\footnotetext{
${ }^{6}$ Um dos documentos mais ricos sobre o valor da dança está em As Bacas, de Eurípedes. O encontro dos velhos Tirésias e Cadmo ilustra bem o caráter rejuvenescedor da dança. "Cadmo: Onde irei dançar? Onde deter o passo e sacudir a cabeça grisalha? (...) Não me fadigaria de noite nem de dia bater com o tirso a terra. É doce esquecer-nos que somos velhos. (...) Tirésias: (...) Dirão que da velhice não me envergonho ao ir dançar, coroada a cabeça de heras? Pois não distingue o Deus quem o jovem e quem o velho se é preciso dançar, (...)" (TORRANO, 1995, p. 59).
} 
Temos ainda a interrogativa "Canção de Domingo", que põe em paralelo significativo para a poesia de Quintana, "dança" e "trança", "canto" e "reza". Parece estar aqui o embrião de dois grandes poemas em que o motivo da dança é central: "Aula inaugural" e "Inscrição para uma lareira" que serão comentados mais adiante.

Além dos três poemas de Canções que se referem à dança, já comentados, temos a "Canção da primavera", primeiro poema em que Quintana alcançou um nível estético mais alto tratando do referido motivo. O poema ficou um tanto esquecido pelos críticos do poeta. Sua análise cerrada poderá nos fornecer elementos mais fortemente caracterizadores de sua poética.

Canção da Primavera

Para Érico Veríssimo

01 Primavera cruza o rio

02 Cruza o sonho que tu sonhas.

03 Na cidade adormecida

04 Primavera vem chegando.

05 Catavento enlouqueceu,

06 Ficou girando, girando.

07 Em torno do catavento

08 Dancemos todos em bando.

09 Dancemos todos, dancemos,

10 Amadas, Mortos, Amigos,

11 Dancemos todos até

12 Não mais saber-se o motivo...

13 Até que as paineiras tenham

14 Por sobre os muros florido!

A presença da redondilha maior, do primeiro ao último verso, confere ao poema um caráter popular, um liame com nossa tradição lírica mais antiga. A rima comparece em apenas três versos, embora o poema ostente rica musicalidade nascida de repetições de palavras - chave, sobretudo "dancemos". Observe-se que rimam os versos 4 (chegando), 6 (girando) e 8 ( bando). A rima sugere a contaminação que a chegada da primavera imprime ao ambiente. O verbo "dancemos" é convocado quatro vezes e de forma gradativa: uma na segunda e três vezes na terceira estrofe, que é a mais musical, mais embalante, onde se sugere a chegada a um ápice, a um estado de inconsciência: "Dancemos todos até / Não mais saber-se o motivo..." 
O título do poema é uma das portas de entrada para sua análise. Uma "canção da primavera", espera-se, deve dar conta do caráter exuberante e encantatório dessa estação. Nietzsche, que estudou a natureza do culto a Dionísio, lança mão da imagem da embriaguez para nos fazer compreender a natureza do culto:

ser-nos-á dado lançar um olhar à essência do Dionisíaco, que é trazido a nós, o mais de perto possível, pela analogia da embriaguez. Seja por influência da beberagem narcótica, da qual todos os povos e homens primitivos falam em seus hinos, ou com a poderosa aproximação da primavera a impregnar toda a natureza de alegria, despertam aqueles transportes dionisíacos, por cuja intensificação o subjetivo se esvanece em completo auto-esquecimento. ${ }^{7}$

A primavera, portanto, parece convocar o "homem primitivo" a cantar e dançar até "não mais saber-se o motivo". O poema nos apresenta a chegada súbita da primavera e, ao mesmo tempo, nos convoca a dançar.

Observemos um pouco a estrutura sintática do poema e os efeitos que resultam de sua construção. A economia verbal é marca do poema. Ela se revela nas elipses do sujeito (v. 2, 6, 8, 9 e 11) e na ausência de descrições. Há apenas convocação e sugestão. As repetições, sobretudo do verbo "dancemos", servem a um propósito rítmico e têm uma função de chamamento para dentro da ação. Não são, portanto, excessivas. Duas inversões sintáticas têm efeito poético nuclear: "Na cidade adormecida / Primavera vem chegando" e "Em torno do catavento / Dancemos todos em bando". Note-se que a inversão confere primazia aos lugares em que se realizará a dança. E há uma gradação que vem de "cidade", espaço maior, para "em torno do catavento", espaço particularizado. Outro ponto a ser destacado é a estrutura paralelística em que se apóia quase todo o poema. Na primeira estrofe ela comparece nos versos 1, 2 e 3; retorna depois, nos versos 8, 9 e 1l. Há, portanto, movimentos sintáticos de retorno que conferem ao poema uma circularidade. Esta circularidade pode reforçar a figuração da cena de dança grupal, das cirandas, sobretudo. Becker chamou a atenção para o fato de que "vamos todos cirandar" praticamente equivale a "dancemos todos dancemos".

Inicialmente a Primavera é animizada: ela "cruza o rio" e "o sonho que tu sonhas". Atentemos para o poder da Primavera de cruzar elementos

\footnotetext{
${ }^{7}$ NIETZSCHE, 1992, p. 30. O caráter dionisíaco de "Canção da Primavera" já havia sido apontada por Bittencourt e mais recentemente foi reforçado por Becker.
} 
distintos: o rio (dimensão física, geográfica) e o sonho (dimensão irracional, do devaneio, onde o inconsciente se revela com sua vasta gama de imagens e signos). A chegada da Primavera, portanto, articula (cruza) duas vertentes da realidade: a física e a psíquica. A reiteração do verbo cruzar nos dois primeiros versos parece indicar a força incontrolável do que chega e modifica a natureza, invade e mobiliza o que estava aquietado. No terceiro e quarto versos da primeira estrofe deparamo-nos com um indicador temporal: ela "vem chegando" na "cidade adormecida", portanto, à noite. Esta chegada noturna da Primavera liga-se à imagem do sonbo que já fora cruzado. Ao chegar à noite ela parece apanhar a todos desprevenidos. O verbo no particípio ("adormecida") indica o imobilismo da cidade, contrariamente à Primavera que "cruza o rio", "cruza o sonho" e "vem chegando". A opção pelo tempo composto no quarto verso nos dá a idéia de prolongamento, do que vai envolvendo lentamente. Ela "vem chegando" e vamos percebê-la através de seus índices, do ritmo novo que imprime às coisas e às pessoas.

Observemos como isto se dá a partir da segunda estrofe. O índice geo-físico da chegada da Primavera é o vento, uma imagem obsessiva do poeta de Alegrete. Para Bittencourt a imagem do catavento "(...) conduz também à idéia de movimento e dança pelo rodar contínuo de suas pás, além de trazer consigo um clima de renovação através da conotação que o elemento 'vento' adquire na obra quintanesca". O 'enlouqueceu' liga-se aqui ao sonho que fora cruzado na primeira estrofe. Ou seja, estamos diante de elementos irracionais, do que não segue os ritmos ditados por uma ordem lógica. Novamente nos deparamos com o fato de que a chegada da primavera imprime uma mudança. A seguir, o eu lírico se mostra na convocação para a festa: "Em torno do catavento/ Dancemos todos em bando." A chegada da Primavera provoca uma contaminação que leva o eu lírico a convocar para a dança coletiva. É o início do ritual. O ritmo da estrofe como um todo é de dança, de movimento repetido: a repetição de "girando", que no gerúndio tem um sabor de presentificação, de retorno contínuo; as nasalizações presentes em catavento, dancemos e bando conferem à estrofe alguma suavidade. O verbo dançar, sempre no imperativo, vai se repetir três vezes ao longo da terceira estrofe e em lugares estratégicos. Observando ainda a segunda estrofe, não há como esquecer a imagem do "Círculo Mágico". Suzane Langer nos deu indicações precisas da importância da dança em círculo para o homem primitivo: 
Mas a dança em círculo realmente simboliza uma das realidades mais importantes na vida dos homens primitivos - o reino sagrado, o círculo mágico. (...) No círculo mágico todos os poderes demoníacos são soltos. O reino mundano é excluído, e com ele, muito freqüentemente, as restrições e propriedades que lhe pertencem.

A sugestão da dança em círculo está representada, sobretudo, nos versos 07 e 08. No entanto, como já apontamos, toda a estrutura do poema, com idas e vindas, com sugestões de circularidade, confirma a idéia de que estamos diante de um poema que quer resgatar o sentido mágico da dança.

Na terceira estrofe a convocação se amplia e envolve "Amadas, Mortos, Amigos", numa mistura que rompe com as contingências temporais. ${ }^{8} \mathrm{~A}$ alegorização desses seres, sem nome, para a grande dança que a Primavera parece insuflar, é também marca da ausência de ordem racional, que escolhe, seleciona. Três vezes "todos" são convocados. E a durabilidade da dança, podemos dizer, do ritual, vai "até / Não mais saber-se o motivo..."

Quando falo em caráter dionisíaco estou pensando nas reflexões de Nietzsche sobre o culto a Dionísio. Destaco três fragmentos do "filósofo da dança" sobre o culto a Dionísio:

01. Sob a magia do dionisíaco torna a selar-se não apenas o laço de pessoa a pessoa, mas também a natureza alheada, inamistosa ou subjugada volta a celebrar a festa de reconciliação com seu filho perdido, o homem. (...)

02. Cantando e dançando, manifesta-se o homem como membro de uma comunidade superior: ele desaprendeu a andar e a falar, e está a ponto de, dançando, sair voando pelos ares. (...)

03. O homem não é mais artista, tornou-se obra de arte: a força artística de toda a natureza, para a deliciosa satisfação do Uno-Primordial, revela-se aqui sob o frêmito da embriaguez.?

O "frêmito da embriaguez" parece ser atingido neste convite a dançar "até/ Não mais saber-se o motivo." O dístico que fecha o poema retoma os versos iniciais. Ou seja, o sinal de encerramento do ritual virá

\footnotetext{
${ }^{8}$ A convocação dos mortos já aparecera no "soneto V" de A rua dos cataventos. 9 NIETZSCHE, 1992, p. 31. A palavra "frêmito" é nuclear na poesia de Quintana. Diria que pode ser comparada ao "alumbramento" de Bandeira.
} 
do andamento da natureza, do seu próprio ritmo. A suspensão temporal que ocorreu só cessará com outro sinal da mesma natureza: "Até que as paineiras tenham / por sobre os muros florido!"

Estamos diante de um poema que representa um momento mítico de encantamento proporcionado pela chegada da primavera. Há uma espécie de desejo de realização ou de envolvimento do eu lírico com os demais, insuflado pela atmosfera primaveril.

Há um resgate da concepção de poesia como algo sem outra finalidade senão conduzir o homem ao reencontro de uma experiência perdida. O poeta seria aquele que busca, com palavras, reencontrar a harmonia que se foi. A poesia de Quintana, do primeiro ao último livro, ostenta esse veio mítico-celebrativo.

\section{A poesia é a dança}

Publicado em 1976, Apontamentos de História Sobrenatural interrompe um longo jejum de livros de poesia de Quintana. É o livro com maior número de poemas e dá continuidade às várias linhas temáticas e opções formais de sua poesia: reflexão metalingüística, a maestria no manuseio do verso livre, a presença marcante do cotidiano, a poetização de instantes de "frêmito", e, sobretudo, o tempo como temática determinante.

A aproximação que vimos seguindo entre o motivo da dança como revelador de um modo de viver o tempo tem peculiaridades no poema "Aula inaugural". Trata-se de um poema emblemático de uma certa concepção de poesia e de vida. Isto é, formaliza-se nele uma poética que, se aponta para a natureza da poesia, enraiza-a numa experiência, num modo de ver e viver a vida.

\section{Aula Inaugural}

01 É verdade que na Ilíada não havia tantos heróis como na guerra do Paraguai...

02 Mas eram bem falantes

03 E todos os seus gestos eram ritmados com num balé

04 Pela cadência dos metros homéricos.

05 Fora do ritmo, só há danação.

06 Fora da poesia não há salvação.

07 A poesia é dança e a dança é alegria.

08 Dança, pois, teu desespero, dança

09 Tua miséria, teus arrebatamentos,

10 Teus júbilos

$11 \mathrm{E}$, 
12 Mesmo que temas imensamente a Deus,

13 Dança como David diante da Arca da Aliança;

14 Mesmo que temas imensamente a morte

15 Dança diante da tua cova.

16 Tece coroas de rimas...

17 Enquanto o poema não termina

18 A rima é como uma esperança

19 Que eternamente se renova.

20 A canção, a simples canção, é uma luz dentro da noit,

21 (Sabem todas as almas perdidas...)

22 O solene canto é um archote nas trevas.

23 (Sabem todas as almas perdidas...)

24 Dança, encantado dominador de monstros,

25 Tirano das esfinges,

26 Dança, Poeta,

27 E sob o aéreo, o implacável, o irresistível ritmo de teus pés,

28 Deixa rugir o Caos atônito...

O título do poema pode ser lido numa perspectiva meramente escolar, conduzindo a uma decodificação instantânea, que remeteria todo o seu conteúdo a um conjunto de proposições de regras, afirmações e conselhos. Parece-nos que é necessário observar melhor o "inaugural", pensando no campo semântico da novidade, da palavra inaugural, primitiva, do anúncio e até mesmo da consagração.

O poema inicia com uma referência à Ilíada, e a ordenação que preside seus personagens remete, imediatamente, à necessidade de ordenação da vida. Essa necessidade se impõe ao poeta que buscará, sempre, dar uma forma ao caos, à danação. A imagem da dança surge aqui como possibilidade de ordenação e, conseqüentemente, de 'acesso' à alegria.

Perpassa o poema um tom exortativo. O fato de dirigir-se claramente a uma segunda pessoa reforça a idéia de que há um ensinamento a ser transmitido. Sua força não está, apenas, na comunicação de uma verdade, mas, sobretudo em suas imagens. "David", a "Arca da Aliança", "a morte", a "cova", "coroas de rima" nos remetem a um certo conteúdo trágico. Há algo inevitável - a morte - diante do qual o único gesto possível (e aconselhável) é dançá-lo. Plasma-se uma atitude que perpassa todos os poemas em que a dança é representada. Não é recomendável a passividade, o desespero, o medo, os arrebatamentos, tudo deve transformar-se em gesto dançante.

A idéia do trágico que está colocada pode ser suportada através desta atitude que privilegia a dança/poesia. O caráter iluminador da poesia é acionado 
através de diferentes imagens: "a rima é como uma esperança"; "a canção (...) é uma luz dentro da noite", o canto "é um archote nas trevas". Essa afirmação do poder da poesia está presente em toda a obra do poeta gaúcho. Num poema também de Apontamentos de História Sobrenatural, ele dirá: "Quem faz um poema salva um afogado".

O poema estrutura-se através de movimentos diversos que se integram na fatura final da interpretação. Do verso 01 a 04 o poeta nos remete à ordenação das personagens da Ilíada, que "eram bem falantes / E todos os gestos eram ritmados como num balé / Pela cadência dos metros homéricos". Essa constatação é o ponto de partida para a afirmação peremptória que está nos versos 05 e 06. A poesia é eleita como possibilidade única de salvação. Essa possibilidade parece ter como escopo a natureza alegre da poesia, que leva o poeta a compará-la com a dança. O motivo da dança entra no poema como uma espécie de indicação de um rumo, de um caminho ou perspectiva de vida.

Do verso 08 ao 15 o poema enumera "os dramas humanos" a serem dançados: "teu desespero", "Tua miséria, teus arrebatamentos, / Teus júbilos", o medo de Deus e da morte. Este procedimento de "redução de tudo à base elementar, e física, do ritmo acompanha a redução dos dramas humanos (...) à vida concreta, tornando-a não apenas suportável, mas também fonte de felicidade."

Temos, a partir do verso 16 até o último, todo um quadro da função da dança e da canção: "A rima é como uma esperança / Que eternamente se renova”, "A canção (...) é uma luz dentro da noite", e uma definição de poeta: "encantado dominador de monstros, / Tirano de esfinges".

A dança se ergue no poema como motivo central, uma vez que é o elemento propiciador do "equilibrio" ou o único instrumento para suportar os "dramas humanos" e resistir ao rugido do "caos atônito". A perspectiva adotada pelo poeta parece-nos bem delineada: a dança é o modo possível de o homem ordenar o caos, dar uma forma (um ritmo) à existência que, por natureza, é desordem e desequilíbrio: "Fora do ritmo só ha danação." Um dado importante a ser assinalado é que o poeta não nos coloca diante de personagens em ação, dançando, antes, formaliza, poeticamente, sua concepção de poesia e vida.

A força do poema não está no ritmo dançante de seus versos, antes, no apelo das imagens, na repetição do verbo dançar no imperativo (novamente o caráter de convocação, já assinalado em "Canção da primavera") e no "estilo elevado". Formalmente, o verso livre, neste poema, engendra um ritmo que articula versos de mais de 20 sílabas a versos formados apenas 
pela aditiva "e". O tempo todo os versos longos são seguidos por versos curtos e vice-versa. O tom exortativo do poema confere-lhe um caráter pedagógico, no sentido mesmo de indicação de um caminho, de configurar-se como guia. Há uma certeza que nos é comunicada. Os elementos lingüísticos que articulam este caráter de "ensinamento" são claros; "só há", "não há", "A poesia é", "Dança como", "Dança diante", "A rima é", "A canção é".

A dança representa no poema a possibilidade de engendrar um modo de viver alegre de um eu que não abdica da dor, do sofrimento. Articula-se aqui toda uma antropologia que tem como princípio não fugir da vida, antes, "dançar a vida". ${ }^{10}$ Se em "Canção da Primavera" somos convocados à dança coletiva, realizada num tempo especial, a chegada da primavera, em "Aula inaugural", articula uma sugestão mais ampla que não se prende a nenhum tempo específico. Isto é, deve-se dançar todos os instantes e situações com que nos deparamos. Se lá deve-se dançar até a embriaguez, aqui a dança tem uma função de resistência ao caos. Diante da dor, da desesperança, da falta de perspectiva, o poeta deve dançar.

\section{Dança e consumação}

Dançar e cantar se encontram novamente neste curto poema que parece guardar uma certa consciência trágica da vida.

${ }^{10}$ A expressão é título de um livro de Roger Garaudy. Nesta obra o ensaísta francês tece considerações importantes sobre a natureza da dança. Destaco alguns fragmentos de sua concepção de dança que se ajustam bem à idéia representada no poema: "Para mim, a dança é não apenas uma arte que permite à alma humana expressar-se em movimento, mas também a base de toda uma concepção da vida mais flexível, mas harmoniosa, mais natural." "Não apenas jogo, mas celebração, participação e não espetáculo, a dança está presa à magia e à religião, ao trabalho e à festa, ao amor e à morte. O homens dançam todos os momentos solenes de sua existência: a guerra e a paz, o casamento e os funerais, a semeadura e a colheita." "Dançar é, antes de tudo, estabelecer uma relação ativa entre o homem e a natureza, é participar do movimento cósmico e do domínio sobre ele." GARAUDY, 1980, p. 57, 13 e 14. 
Inscrição para uma lareira

01 A vida é um incêndio: nela

02 dançamos, salamandras mágicas.

03 Que importa restarem cinzas

04 se a chama foi bela e alta?

05 Em meio aos toros que desabam,

06 cantemos a canção das chamas!

07 Cantemos a canção da vida,

08 na própria luz consumida...

Por que uma inscrição para uma lareira? Normalmente encontramos inscrições em determinados monumentos, em lápides, em praças e outros espaços públicos. A lareira está associada aos espaços internos das residências. A eleição dela como digno para inscrição é curiosa. Diferentemente dos modernos sistemas de aquecimento alimentados por gás ou energia elétrica, a lareira conserva para os homens um certo fascínio. É o fogo domesticado. O colorido e a dança das chamas, o aquecimento que proporciona, a rapidez com que destrói o que a alimenta, tudo isto produz fascínio.

A sintaxe do poema é simples, sem inversões complexas. Temos um cavalgamento do primeiro para o segundo verso. O sentido como que desliza para o seguinte num rápido passo de dança. Um fato curioso é que o poema se constrói sintaticamente em blocos de dois versos. De fato é como se tivéssemos quatro dísticos. Há ainda uma contaminação da primeira parte do poema na segunda (ou vice-versa). Os versos 5 e 6 nos oferecem uma significativa inversão sintática. Primeiro a localização espacial ("em meio aos toros"), depois a ação ("cantemos a canção").

O primeiro verso é uma afirmação peremptória, acabada. Esse modo de dar início ao poema construindo uma imagem com o verbo de ligação é muito recorrente na poesia de Mario Quintana. ${ }^{11}$ A aproximação entre

${ }^{11}$ Alguns exemplos retirados do livro Apontamentos de história sobrenatural: "A vida é tão bela que chega a dar medo (...) A vida é nova... (...) A vida é nova e anda nua." ("O adolescente", p. 11); "A pantera é uma curva em movimento": ("Crônica", p.12-13); "O mundo é um búzio oco,/ menino..." ("Canção", p. 16/ 17); "O tempo é uma tela que precisa ser tecida"... ("Vida", p. 29); "O tempo é indivisível. (...) "A vida é indivisível. (...) "Todos os poemas são um mesmo poema," ("Pequeno poema didático", p. 30); "Poeta é o que encontra a moedinha perdida..." ("Descobertas", 41); "O teu silêncio é imemorial como as pirâmides" 
incêndio e vida aparentemente não nos coloca nenhum problema, não traz dificuldades para o leitor. O incêndio conota destruição rápida, violência, mas também é luz, imagens surpreendentes. Depois da afirmação inicial, seguida de dois pontos vem outra afirmação curiosa: "Nele dançamos". Somos, na perspectiva do poema, dançarinos do fogo, portanto, "salamandras mágicas". Magia é palavra recorrente na obra de Quintana.

Veja-se ainda que o dístico é todo afirmativo. Os dois versos seguintes nos colocam diante de uma afirmação disfarçada de interrogação. Há uma certeza: do incêndio restarão cinzas, mas isto não é o mais importante. O que importa é o processo, o percurso da dança. Isto é, importa que a chama seja "bela e alta". De fato, estamos no estatuto da vivência do instante, do brilho singular de cada chama. A imagem da dança está intimamente ligada a esta idéia do instantâneo, do fugaz. Esta idéia se corporifica de modo mais claro no dístico seguinte. O que poderia parecer trágico para uns, aqui não é. Ou seja, em meio à destruição, à consumação que se dá a cada instante somos convocados a dançar e cantar. A consciência do fato inevitável da consumação não conduz a um afastamento ou desencanto com a vida. É necessário viver o calor do instante, estar aberto e deixar-se consumir. Tratase portanto de um curioso "carpe-diem". Viver o instante que passa, dançálo e cantá-lo. Viver a própria fugacidade de modo completo, consumir-se nela. A imagem do fogo percorre o poema, atualizada em imagens que vão do título ao último verso: "lareira", "incêndio", "salamandras", "chama", "chamas", "luz consumida".

A idéia de que é preciso dançar a vida retorna aqui não mais apenas como convocação; ela se realiza. Ela está aliada a uma profunda consciência da condição humana, efêmera, passageira. A "sabedoria" estaria em dançar e cantar, pouco importando se vão restar "cinzas". A atitude do poeta é de quem acredita que o sentido da vida reside em viver a intensidade do instante. A consciência aguda de que a passagem pela vida é rápida e está a cada momento desmoronando é que conduz o eu lírico a esta postura, diríamos, existencial.

("Dois versos para Greta Garbo", p. 71) "Deus émais simples do que todas as religiões". ("Dogma e Ritual”, p. 78); "O mundo é frágil/ E cheio de frêmitos/ como um aquário..." ("Momento", p. 93). 


\section{Dançar a vida}

A dança assume ao longo da obra de Quintana um sentido que consiste basicamente em elevar-se a modelo ideal de vivenciar o instante. Dançar vai assumir, como vimos em "Aula inaugural", um paradigma para o homem enfrentar as diferentes situações que a vida apresenta. Todas as experiências de sofrimento, angústia, incerteza, medo, indecisão podem ser dançadas. O tom convocatório e imperativo do poeta confere aos poemas um caráter de poética.Poética de uma pedagogia. A convocação à dança em diferentes momentos tem em seu cerne uma marca primitiva, uma espécie de reaprendizagem do homem. O poeta não nega a razão, a reflexão como instrumento essencial para o homem enfrentar as dores da vida. Antes, chama a atenção para uma outra perspectiva. Isto é, dançar cada experiência, seja qual for sua natureza. Para um homem moderno, marcado por séculos de racionalismo, que acredita na máxima de Descartes - "Penso, logo existo" - esta "nova" lógica do poeta talvez soe fora de tempo, até mesmo superficial. É como se a máxima do poeta fosse: "danço, logo existo". Não creio que a perspectiva apontada por Quintana se contraponha a isto ou àquilo. Trata-se de algo possível que, a meu ver, nasce duma espécie de reaprendizagem da vida. Não de voltar ao primitivo, antes, de reencontrar, no primitivo, formas de viver que nosso racionalismo foi deixando de lado. Esta abertura que o poeta aponta ligase, portanto, a tradições culturais antiqüíssimas, a experiências culturais consideradas anacrônicas; ao modo mítico, enfim.

Vimos ao longo das análises perseguindo a hipótese de que o motivo da dança, acionado na poesia de Quintana, está intimamente ligado ao modo do poeta conceber a vivência do tempo. Cada poema analisado revela uma nuança nova neste quadro de representação da dança. A dança, pelo que tem de fugidio, de encantatório, pela alegria que possibilita, pela suspensão do tempo histórico que pode provocar, torna-se uma espécie de imagem-paradigma para o poeta. A vida e seus dramas podem ser dançados e essa opção não se constitui num fugir do real, num esconderse; antes, trata-se de criar um ritmo para cada situação, dançar cada adversidade, mesmo a mais trágica, a mais dolorosa. Essa postura talvez represente uma novidade da poesia de Quintana e está ligada a diversas tradições culturais e até mesmo a determinadas correntes de pensamento. A insistência do poeta nesse motivo e o modo como o faz conferem à sua poesia um lugar de destaque em nossa tradição lírica. 


\section{Referências Bibliográficas}

MEIRELES, Cecília. Crônicas em geral - tomo I. Rio de Janeiro: Nova Fronteira, 1998.

Euripedes. As Bacas. (Tradução e estudo de Jaa Torrano). São Paulo: Hucitec, 1995.

NIETZSCHE, Friedrich. O nascimento da tragédia. Trad. Jacó Guinsburg. São Paulo: Companhia das Letras, 1992.

GARAUDY, R. Dançar a vida. 6. ed. Rio de Janeiro: Nova Fronteira, 1980.

\section{Resumo}

A presença do motivo da dança na poesia de Mário Quintana e sua possível interpretação

\section{Résumé}

Cette article étude la fonction du motif de la danse dans la poésie de Mário Quintana. 